\title{
O olhar feminista e o processo de criação de Deslady ${ }^{1}$
}

\section{The feminist gaze and the creative process of Deslady}

\author{
Margie Rauen ${ }^{2}$ \\ Angélica R Kauffmann ${ }^{3}$
}




\section{Resumo}

Este artigo aborda o olhar feminista em Deslady (Curitiba, 2018), adaptação da peça Macbeth, de William Shakespeare, para um solo de Nathalia Luiz, a palhaça Tinoca. Discute-se a identidade violenta de Lady Macbeth, as relações de poder e a loucura, expondo a ganância e a falta de liberdade nas práticas culturais androcêntricas de poder. São citados depoimentos oferecidos por mulheres artistas participantes da equipe de criação, ilustrando as suas percepções enquanto agentes de composição. Consideram-se as múltiplas codificações de teatro e de palhaçaria feminina nas máscaras da Palhaça Tinoca, de Lady Macbeth e de Deslady.

Palavras-chave: feminismo; dramaturgia; apropriação; participação

\section{Abstract}

This paper appraises the feminist gaze in Deslady (Curitiba, 2018), an adaptation of William Shakespeare's Macbeth for a solo performance by Nathalia Luiz, whose clown name is Tinoca. The discussion centers Lady Macbeth's violent identity, the power relations and madness, exposing the greed and lack of freedom in androcentric cultural practices. Testimonies offered by women who joined the creation team are quoted in order to illustrate their perceptions as agents of composition. The multiple codes of theater and of female clown practice in the roles of Tinoca, Lady Macbeth and Deslady are addressed.

Keywords: feminism; dramaturgy; appropriation; participation

\footnotetext{
${ }^{1}$ A estréia da peça Deslady foi em Curitiba, aos 08/08/2018. Produzida pela Companhia dos Palhaços, por meio da Lei Municipal de Incentivo à Cultura da Fundação Cultural de Curitba, foi apresentada de 10 de agosto a 2 de setembro de 2018, no Espaço Fantástico das Artes (Al. Princesa Izabel, 465 - São Francisco, Curitiba). Nathalia Luiz, a palhaça Tinoca, foi a idealizadora e incorpora este solo ao seu repertório. A agenda de circulação abrange festivais, escolas e contrapartida social em instituições municipais e estaduais diversas.

${ }^{2}$ Nome artístico de Margarida Gandara Rauen, Ph. D. em Teatro, Michigan State University, E.U.A. Visiting Fellow da Warwick University (2017). Aposentou-se como professora Associada do Departamento de Arte da UNICENTRO e permanece docente colaboradora do Programa de Pós-graduação em Educação (PPGE). margierauen.br@gmail.com
}

${ }^{3}$ Nome artístico de Angélica Mayara Gonçalves Rodrigues, Mestre em Letras pela UFPR. Dramaturga, dramaturgista e diretora teatral. angelica.emcena@gmail.com 
Feministas são mulheres que não gostam de homens? Feministas são pessoas infelizes? Feministas são pessoas de esquerda, seguidoras de Friedrich Engels e Karl Marx? Não necessariamente! Isto porque nem todas as pessoas feministas desgostam de homens, são infelizes e/ou de esquerda. A aversão por homens, a infelicidade e a compatibilidade intelectual com ideologias socialistas ocorreram em diferentes contextos sociais, regiões e épocas muito antes das noções atuais de esquerda marxista. No entanto, o desconhecimento do tema e os estereótipos relacionados ao termo feminismo acarretam a reprodução dos clichés anti-feministas vistos nas perguntas iniciais. Alice S. Rossi (1973) apresenta textos feministas fundadores escritos durante o século XVIII, ${ }^{4}$ destacando Da Igualdade dos Sexos, de Judith Sargent Murray (17511820) e Reivindicação dos Direitos da Mulher, de Mary Wollstonecraft (1759-1797). Se considerarmos a trajetória histórica de mulheres mentoras e educadoras, existiram ativistas e reivindicadoras de equidade de gênero desde a antiguidade clássica, tais como Hipátia de Alexandria, assassinada em 415 d.C. e vítima de misoginia.

O que é, então, um olhar feminista? De modo suscinto, o olhar feminista é aquele a partir do qual alguém problematiza as relações androcêntricas de poder e examina modos de existir emancipatórios de mulheres. Neste artigo, o olhar feminista é central na apresentação de nossa prática artística no processo de criação da peça Deslady (Curitiba, 2018), um solo da atriz Nathalia Luiz, a palhaça Tinoca, com dramaturgia de Angelica R. Kauffmann e direção de Andréa Macera, ${ }^{5}$ livremente inspirada em Macbeth e na personagem Lady Macbeth, de William Shakespeare (1564-1616).

Compreender os elementos do olhar feminista foi crucial no processo de criação de Deslady porque, sem os mesmos, não seria possível problematizar o teor androcêntrico da peça de Shakespeare. Dentre as inúmeras causas feministas, a violência e a falta de autonomia nas relações de poder foram os temas priorizados em Deslady, mas a peça também deixa claro que mulheres, tanto quanto homens, podem deter o poder segundo uma lógica utilitarista, reproduzindo modelos de opressão e se aprisionando nas próprias tramas, conforme ocorre em Macbeth. Simone de Beauvoir (2009), Michelle Perrot (2006) e Chimamanda Ngozi Adichie (2012), além de Pierre Bourdieu (2012) proporcionaram uma retrospectiva histórica na pesquisa sobre a problemática feminista e um repertório para a leitura critica de Macbeth.

No primeiro tópico deste texto, apresentamos considerações sobre aspectos da peça de Shakespeare que foram priorizados na seleção de conteúdo para a transposição e composição de Deslady, abrangendo as fontes e os sentidos de palhaço no século XVII. No segundo tópico, temos a perspectiva da dramaturgista, complementada por depoimentos da atriz Nathalia Luiz e, finalmente, por depoimentos de integrantes da equipe de criação. Optamos por usar Deslady em itálico sempre que nos referimos ao nome da peça, e sem itálico quando nos referimos a uma das máscaras/personagem.

\footnotetext{
${ }^{4}$ Mulheres feministas já haviam produzido a maior parte de seus escritos na segunda metade do século XVIII antes do nascimento de Karl Marx (1818-1883) e Friedrich Engels (1820-1895).

${ }^{5}$ Ficha técnica disponível em http://ciadospalhacos.com.br/espetaculos/espetaculo-deslady/
} 


\section{A apropriação Shakespeareana, os palhaços e as mulheres}

Macbeth é a tragédia mais curta de Shakespeare e a primeira publicação da peça apareceu em 1623 (in Folio, primeira edição completa de peças atribuidas a Shakespeare). A maior parte da ação ficcional transcorre na Escócia, indo da região de Forres, para Inverness, Fife e Dunsinane (com floresta de Birnam), mas há cenas na Inglaterra. Forres, na costa norte da Escócia, fica a cerca de $40 \mathrm{~km}$ de Inverness. $O$ feudo ou condado medieval de Cawdor, que passa ao controle do Macbeth ficcional, situava-se entre Forres e Inverness. Fife também segue sendo uma cidade histórica, cuja distância de Inverness é de $218 \mathrm{~km}$ ao sudeste. Dunsinane fica a cerca de $60 \mathrm{~km}$ ao norte de Fife. Um mapaemento ilustra o quanto as cenas "viajam" por longa extensão de território, fato que em si seria divertido para o público da época, pensando em viagens a pé, a cavalo ou de carroças. ${ }^{6}$

A principal fonte da Shakespeare para Macbeth é Holinshed (1587) e suas narrativas de episódios históricos violentos e sangrentos da Inglaterra e da Escócia, incluindo trechos sobre Gruoch, nome da Lady Macbeth histórica. Segundo Holinshed, Gruoch era viúva de Gillacomgain, filho mais velho do irmão de Finlay, pai de Macbeth. Quando solteira, Gruoch foi uma princesa na linhagem patriarcal de Malcolm II (rei da Escócia entre 1005 e 1034). O irmão dela seria o successor do rei Malcolm II, mas este determinou que o neto, Duncan, o sucederia. Finlay reinava em outra região independente da Escócia, chamada Moray, mas foi assassinado pelo sobrinho, Gillacomgain, o qual passou a controlar Moray. Macbeth, mais jovem que seus primos usurpadores, fugiu e exilou-se na Irlanda. Em 1020's, Gruoch se casou com Gillacomgain. Foi uma união estratégica, tendo em vista as conexões de Gruoch com o rei da Escócia, Malcolm II. Lulach, filho de Gruoch e Gillacomgain, tornou-se um potencial sucessor ao trono da Escócia. Em 1030, Macbeth voltou do exílio para se vingar e provavelmente asssassinou o seu primo Gillacomgain durante uma festa. Em seguida, Macbeth casou com Gruoch e se tornou padrasto e protetor de Lulach, como se fosse seu herdeiro. O casamento de Macbeth com Gruoch consolidava a hereditariedade na sucessão ao trono da Escócia, enquanto Malcolm II envelheceu e continuou reinando.

Para Holinshed e outros historiadores do século XVII, os motivos de Gruoch para casar com o assassino de seu primeiro marido e pai do seu filho costumam ser relacionados ao desejo de proteger Lulach. O irmão de Gruoch também foi assassinado, aparentemente a mando do rei Malcolm II, para garatir a sucessão de Duncan, que ocorreu após a morte de Malcolm II em batalha, na região de Glamis, em 1034. Duncan não era idoso e não foi assassinado no castelo de Macbeth (como na peça de Shakespeare). Os historiadores especulam que pode ter sido morto por Macbeth em 1040, quando o desafiou em batalha para recuperar o reino de Moray. A viúva e os filhos de Duncan fugiram para a Inglaterra e Macbeth foi coroado. Reinou por 17 anos ao lado de Gruoch e trouxe prosperidade para a Escócia. Idoso, Macbeth abdicou em 1057, em favor do enteado, mas Lulach foi morto em batalha contra Malcolm III, filho de Duncan, em 1058. Macbeth tentou defender o direito do filho de Lulach ao trono,

${ }^{6}$ Mapa disponível em: https://www.thinglink.com/scene/483009105884086274 
mas foi morto em nova batalha e sepultado no cemitério real de lona. A fonte não menciona os dias finais de Lady Macbeth, mas historicamente, não existe evidência de que tenha sido assassina ou suicida. Em resumo, na adaptação Shakespeareana de Holinshed, Lady Macbeth é uma personagem gananciosa e ambiciosa, focada na preservação da linhagem patriarcal do mundo medieval ao qual pertence.

Macbeth não tem uma personagem palhaço, mas a opção por palhaçaria, no processo de criação de Deslady, pressupõe uma relação com os clowns shakespeareanos. Pesquisadores(as) tendem a dividir a ocorrência de palhaços na dramaturgia de William Shakespeare em dois grandes grupos: o dos toscos (rustics) e o dos bobos (jesters e/ou fools), sempre homens provocadores de estranhamento social no drama satírico (Dorneles, 2003; Ramalho, 2009). A função dos toscos é provocar o riso e estão associados a algum comportamento característico de pessoas não pertencentes à corte, as quais se expressam em linguagem de seu grupo cultural e são percebidas como ingenuas ou ignorantes. Quanto aos bobos, acredita-se que apenas divertiam as cortes da Inglaterra desde o século XII, fossem eles classificados como naturais ou como artificiais. Os bobos naturais eram tratados como mascotes e, hoje, seriam considerados vítimas de abuso e booling, pois muitos eram deficientes físicos e/ou mentais, expostos ao ridículo para alimentar o riso preconceituoso. Os bobos artificiais como Touchstone (de Como Gostais), Feste (de Twelfth Night) e o bobo anônimo de Rei Lear aparecem com mais frequencia nas peças de Shakespeare e se diferenciam como pensadores à margem do sistema (outsiders), por sua sabedoria, humor e perspicácia, sempre questionando as lógicas de poder. ${ }^{7}$

$\mathrm{Na}$ época de Shakespeare, o teatro era um campo de homens. Acredita-se que as personagens mulheres eram feitas por meninos, aspecto bem conhecido da prática cênica que proibia o trabalho de atrizes, embora haja controvérsias. Ann Thomson (1996), por exemplo, questiona a regra da não existência de atrizes antes dos anos 1660, apesar de reconhecer a importância da diacronia das primeiras atrizes inglesas feita por Elizabeth Howe (1992). Hoje, a história da participação de mulheres nas práticas de dramaturgia e teatro shakespeareanos é um campo extenso (McMullan, Orlin \& Vaughan, 2014), que também se desenvolveu no Brasil, onde contextualizamos o projeto e realização de Deslady por Nathalia Luiz e sua equipe artística de mulheres, segundo a abordagem da palhaçaria feminina.

Surpreendentemente, Santos (2014), em um dos escassos estudos sobre a presença feminina no modo de organização do circo brasileiro, verificou que, ainda no século XX, a mulher palhaça era invisível porque se transvestia de homem para poder atuar:

A constituição da mulher palhaça está referendada em elaborações e implicações sociais, políticas e estéticas sobre as diversas atuações femininas na sociedade. Assim, até o inicio do século XX, esta construção cênica específica nos circos ainda era voltada para o homem e muitas mulheres para atuar nesta linguagem, apareceram escondidas sob as roupas do palhaço. (Santos, 2014, p. 20)

${ }^{7}$ Uma versão anterior deste parágrafo, assinada pela assistente de direção e consultora de pesquisa, encontra-se no programa da peça (2018). 
Tal qual ocorreu no ambiente de teatros, portanto, a palhaçaria feminina esteve sujeita a discriminação e preconceitos. Além disso, mulheres nos números de circo geralmente representavam estereótipos de sensualidade, destreza e beleza física (Bolognesi, 2003).

\section{A dramaturgia de Deslady e a percepção da equipe de criação}

As dinâmicas de composição dramatúrgica e cênica de Deslady estiveram diretamente conectadas à idealização do projeto, em que todas as agentes criativas influenciariam a obra. Esse processo assemelhou-se ao que chamamos de processo colaborativo, que difere de criação coletiva. Para compreendermos estas duas dinâmicas explicitaremos, primeiramente, o que se define por processo colaborativo, segundo um trecho da tese do diretor da companhia teatral Teatro da Vertigem, Antônio Carlos de Araújo Silva, mais conhecido, no meio artístico, como Antônio Araújo:

A referida dinâmica - numa definição sucinta - se constitui num modo de criação em que cada um dos integrantes, a partir de suas funções artísticas específicas, tem espaço propositivo garantido. Além disso, ela não se estrutura sobre hierarquias rígidas, produzindo, ao final, uma obra cuja autoria é dividida por todos. (Araújo, apud Carreira, 2008, p.1)

Se, por um lado, Antônio Araújo não separa ou distingue, tão evidentemente, criação coletiva de processo colaborativo, a pesquisadora Sílvia Fernandes afirma haver "[...] semelhanças entre os dois procedimentos, mas que eles não chegam a se confundir" (Fernandes, 2002, p. 36). O ponto de distanciamento entre os processos estaria relacionado ao texto. Na criação coletiva, todos os participantes igualmente contribuem para a criação dramatúrgica, e mesmo que alguém se encarregue da organização do texto, não lhe cabe o papel de autor. Já o processo colaborativo conta, a priori, com a figura de um dramaturgo, mas não deixa de incluir o diálogo. Neste caso, o/a dramaturgo(a) escreve a peça paralelamente ao processo de criação, fazendo cortes, modificações, e tendo como o espetáculo como ponto de partida. Contudo, todos os agentes criativos colaboram para a formação do texto ao realizarem, por exemplo, jogos de improvisação, tanto de fala quanto corporais e ao trazerem propostas de encenação. Tudo isso altera a dramaturgia.

A descrição acima aplica-se diretamente ao processo de Deslady, cuja dramaturgia é assinada por Angélica R. Kauffmann mas parte dos improvisos da atriz Nathalia Luiz (e sua palhaça Tinoca) e da peça Macbeth, de William Shakespeare. A fábula desenvolvida em Deslady parte da narrativa em que uma atriz é expulsa de um grupo de teatro clássico e sai pelo mundo tentando encenar Macbeth sozinha. Imersa nesse conflito, a palhaça se mostra uma dependente de remédios tarja preta, por causa dos danos psicológicos causados pela sociedade machista e, por conseguinte, sob os efeitos da opressão que a mulher sofre, incluindo as pressões estéticas, as violências físicas e psicológicas, a objetificação do corpo feminino e a desvalorização do seu trabalho em relação ao do homem. Na fábula, essas questões se apresentam no diálogo constante entre a personagem Lady Macbeth e o seu marido Macbeth, que 
é desenhado como um homem "frouxo", incapaz de realizar sozinho as atrocidades que deseja.

O texto de Deslady é composto de um prólogo e 11 cenas. O prólogo é um aúdio que contextualiza quando a palhaça foi expulsa da companhia de teatro clássico da qual fazia parte. Da cena 1 até a cena 9, a palhaça sempre fica nervosa e recorre a uma caixa de remédios que ela guarda em sua roupa. Descrevemos, em seguida, cada cena:

Cena 1- Equilíbrio: abre o espetáculo, com a palhaça equilibrando diversos objetos com o corpo e indicando os diversos tipos de equilíbrio que a mulher realiza na vida.

Cena 2 - Montagem do espaço: a palhaça, com ajuda de um voluntário da platéia, monta o espaço e ironiza a questão da inferiodade da força física feminina em relação a masculina.

Cena 3 - Número do aquecimento: a palhaça realiza seu aquecimento corporal brincando com exercícios típicos do teatro.

Cena 4 - Leitura: a palhaça começa a ler a história de Shakespeare e vai se dando conta o quão violenta é a narrativa; ora se espanta ora encarna ferozmente a violência descrita.

Cena 5 - Poder: com os trajes e vivenciando a máscara de Lady Macbeth, a palhaça mostra todo o autoritarismo presente da personagem.

Cena 6 - Encenação da peça dentro da peça: a palhaça auxilia a Lady com a montagem de Macbeth e, nesse momento, a palhaça percebe que não a conhece tanto assim e será imposssível montar a peça de Shakespeare sem ajuda da platéia; ela convoca homens para fazerem as personagens de Banquo, Duncan e Macbeth.

Cena 7 - Duelo entre Lady e Palhaça: tomada pelo autoritarismo da Lady, a palhaça entra em uma espécie de surto e duela consigo mesma, tentando se libertar das forças da Lady.

Cena 8 - Leitura trágica da Invocação: a palhaça é dominada pela Lady enquanto declama um trecho da peça Macbeth.

Cena 9 - Morte da Lady: a palhaça consegue emergir e retoma consciência através dos ecos de todas a mulheres que a ajudam a se reequilibrar. Nesta cena, simula-se o suícidio da Lady após enlouquecer com o poder, retomando a fonte shakespeariana.

Cena 10 - Desvelamento e poder: a palhaça se liberta da dominação e da violência da Lady e do poder machista que ela representa. O cetro vira a caneta do poder contemporâneo e ela pede que pessoas do público tomem a caneta e digam o que fariam se tivessem poder.

Cena 11 - Invocação da Deslady: a palhaça, agora emancipada, faz uma invocação sobre o poder feminino e vislumbra a transformação.

Os trechos de Shakespeare utilizados foram compilados da tradução de Beatriz Viegas-Faria para a língua portuguesa brasileira, na reimpressão de abril de 2016, da L\&PM Pocket (Shakespeare, 2016). Foram utilizados fragmentos de 4 trechos da peça (Shakespeare, 2016, p. 29, 34, 35 e 43). O trecho mais longo integra o que intitulamos invocação, quando a personagem Lady Macbeth apela para todas as forças sombrias 
e deseja a liberação de seu sexo feminino para poder realizar o assassinato planejado. Além da liberação de seu sexo, a Lady invoca uma espécie de permissão porque, sendo mulher, na época, ela não poderia realizar ações tradicionalmente permitidas somente aos homens. Cenas de Shakespeare, portanto, foram apropriadas para a criação de uma nova fábula, na qual Lady Macbeth representa o poder violento e é colocada em diálogo com questões contemporâneas de mulheres. Ao refletir sobre o olhar feminista, a atriz e palhaça Nathalia Luiz afirma que ela mesma é

\begin{abstract}
... uma Palhaça com uma grande convivência e referência em uma formação masculina. Há mais ou menos 4 anos é que venho desenvolvendo mais o meu lado feminista e consequentemente empoderando mais a minha Palhaça. Eu me sinto muito feliz e honrada por estar defendendo agora a arte da palhaçaria feminina através do meu trabalho enquanto mulher, Palhaça e atriz. Acredito que quando se cria um solo isso ganha uma força enorme. Sempre tive um estilo de Palhaça muito feminina, mas não necessariamente feminista. E com esse espetáculo não levanto a bandeira feminista, mas estou falando diretamente ou indiretamente sobre essa temática. Deslady é um espetáculo para todos os gêneros, mas a ideia é que todos saiam refletindo sobre essa cultura machista que precisa ser transformada e consequentemente que as pessoas possam repensar suas culturas e até mesmo a se deseduquem de algumas coisas que ficaram enraizadas em cada ser humano, independente do sexo. Inclusive conheço muitas mulheres machistas, que nem sabem que são, pois aprenderam assim. (Fonte: Depoimento de Nathalia Luiz, por e-mail)
\end{abstract}

A primeira cena, em que a palhaça entra equilibrando diversos objetos com o corpo (Imagem 1), ilustra esse teor cultural descrito pela atriz. A cena foi construída a partir das improvisações de um número clássico de equilíbrio realizado por palhaços e foi ganhando outras proporções, ao entrar em diálogo com a temática do equilíbrio em um sentido mais amplo. A partitura corporal orientada por Marina Prado modificou-se com as transformações de um simples bastão circense em um cetro do poder e, ao mesmo tempo, em uma caneta que remonta aos poderes políticos atuais, indicados pela assistente de direção. Por fim, a cena ganhou outras miríades com a inserção de falas sobre o equilíbrio da mulher ao longo de sua vida, feitas posteriormente pela dramaturgista e decorrentes da pesquisa sobre feminismos.

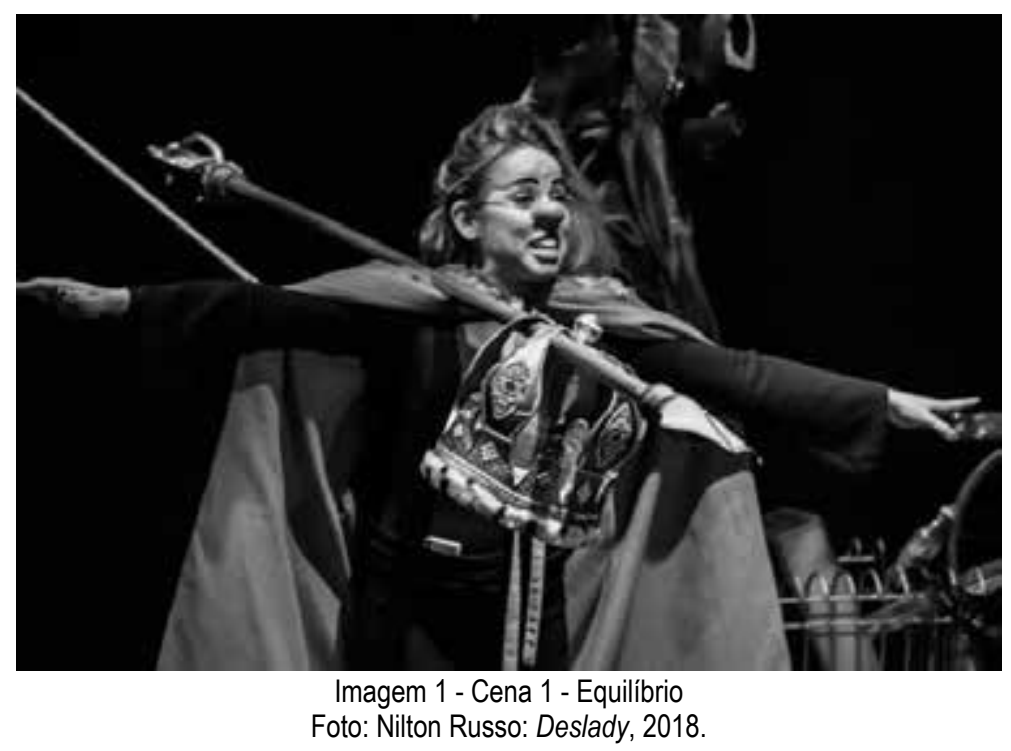


Na Cena 6 - Encenação da peça dentro da peça, ocorreu um processo inverso e a solução partiu da dramaturgia. O objetivo da direção e da palhaça era de criar uma cena em que um trecho da peça Macbeth fosse reencenado com o público. Deste modo, a dramaturga propôs que a palhaça resolvesse contar os personagens presentes na obra e se desse conta que existem mais de 30. Isso a impulsionou a simplificar a narrativa de assassinatos e realizar um jogo com participacão do público (imagem 2).

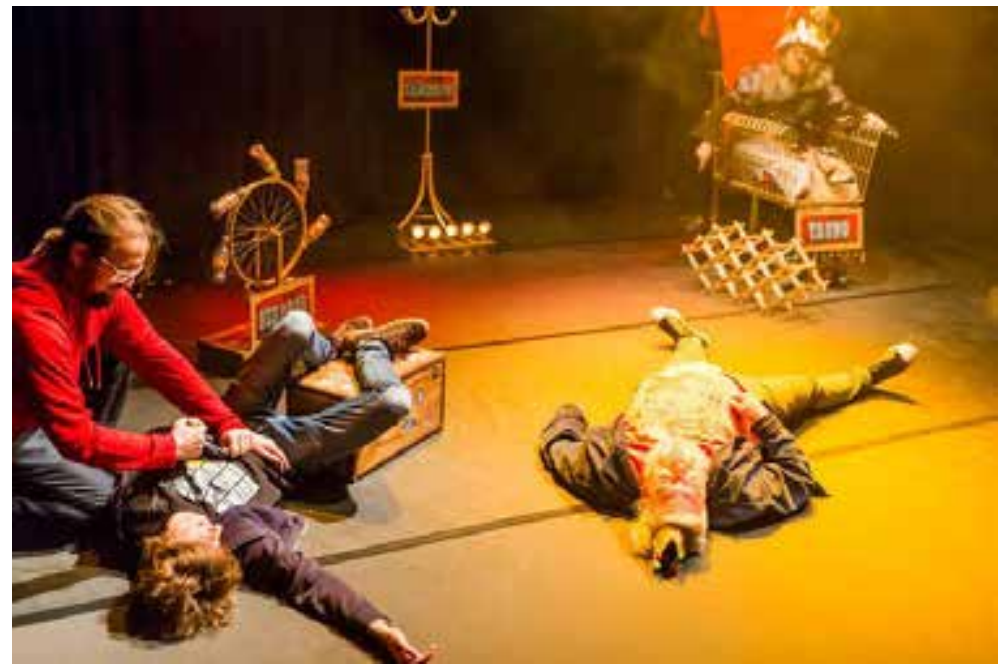

Imagem 2 - Cena 6 - Peça dentro da peça

Foto: Nilton Russo: Deslady, 2018.

No concernente à apropriação de Macbeth, observamos que, mesmo tratando-se de um processo de adaptação, ou neste caso, uma transposição da obra, o nome Shakespeare sempre paira no ar. Em relação a esta sombra que um texto canônico carrega, uma espécie de fantasma, a teórica Linda Hutcheon (2013, p. 27) afirma que: "[...] trabalhar com adaptações como adaptações significa pensá-las como obras inerentemente 'palimpsestuosas'", ou seja, o espectro da obra fonte estará sempre retornando à mente do público. Seria impossivel trabalhar com uma adaptação e esquecer totalmente da obra fonte, mesmo quando a transposição é totalmente diferente se, ao anunciar a adaptação, o/a artista, já no título, faz uma alusão que permanecerá na obra e em sua recepção. Em Deslady, a solução encontrada para reconhecer esta sombra foi a utilização poética da palhaça/atriz ao "brincar" com o nome Shakespeare, em uma tentativa de dessacralização ou desmonumentalização da figura do autor (Rauen, 2005).

Além de os estereótipos prejudicarem a compreensão da postura feminista, reconhecer a cultura e ironiza-la também foi essencial no processo de criação. Adichie (2012, p. 46-47) aponta o estereótipo machista de que "[...] a mulher usa a sexualidade para conseguir o que quer do homem. Mas o poder da cintura para baixo não é nenhum, porque a mulher que tem tal poder, na verdade, não é poderosa. Ela só tem uma boa ferramenta para explorar o poder de outra pessoa".

O poder e o seu uso são centrais no Macbeth de Shakespeare e em Deslady. A palhaça passa por três momentos, ou como indicaria a diretora Andréa Macera, três máscaras, sendo a primeira apenas a palhaça (imagem 3), a segunda a palhaça contaminada pela Lady Macbeth (imagem 4) e a terceira, a Deslady (imagem 5) 


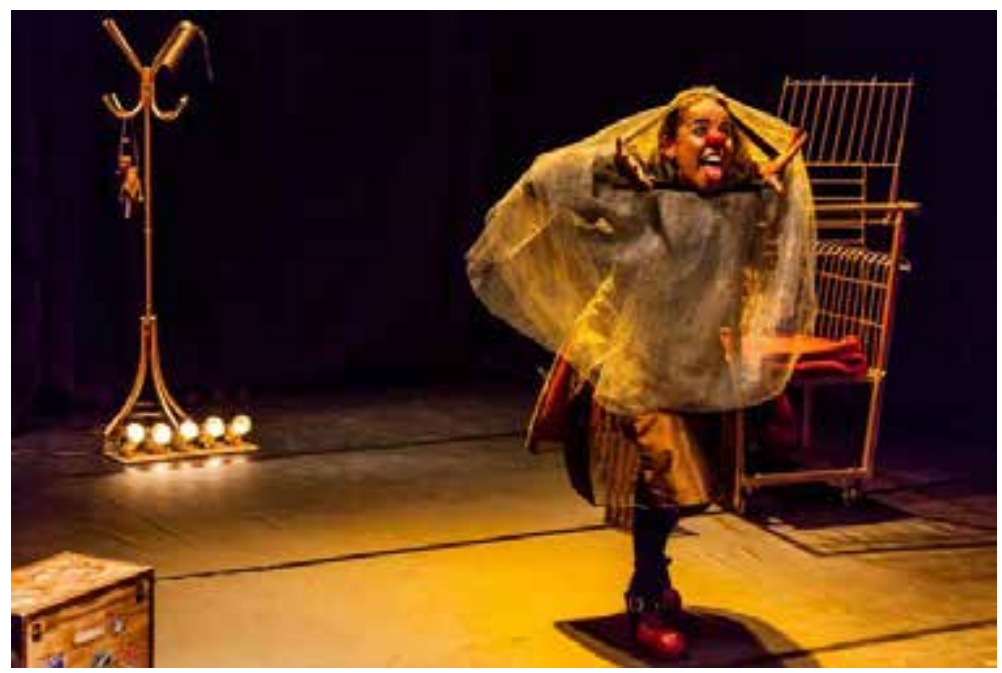

Imagem 3 - Máscara Tinoca

Foto: Nilton Russo: Deslady, 2018

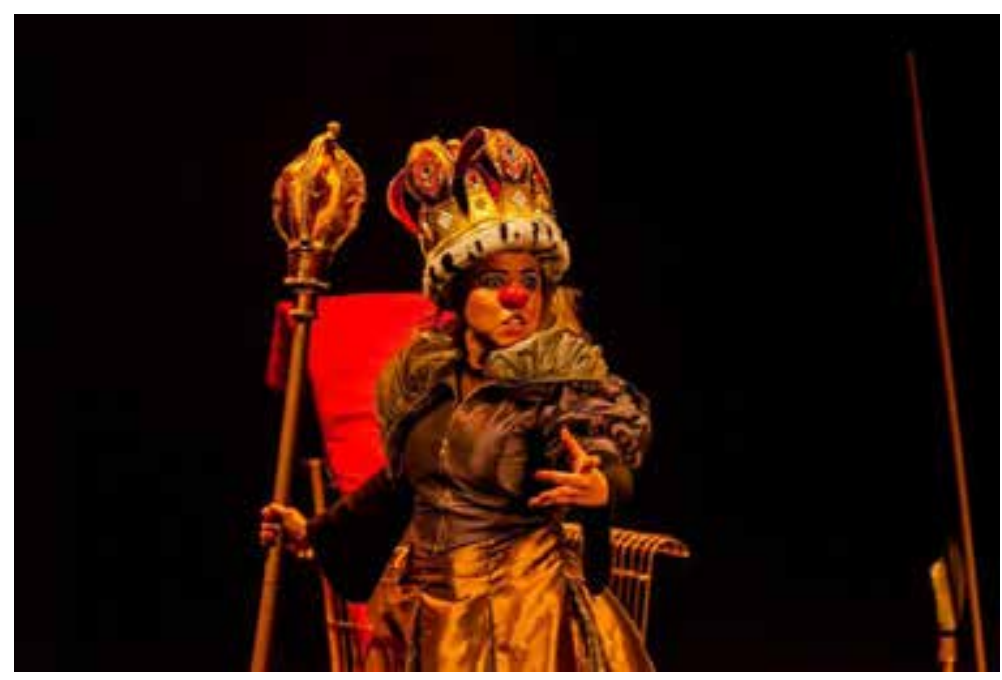

Imagem 4 - Máscara Lady Foto: Nilton Russo: Deslady, 2018.

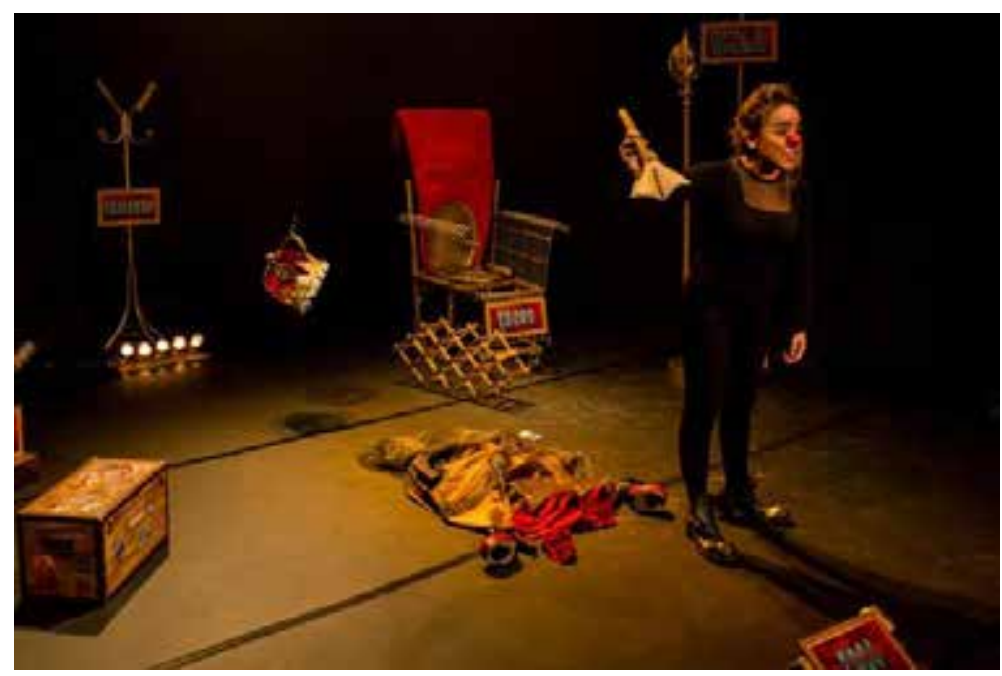

Imagem 5 - Máscara Deslady

Foto: Nilton Russo: Deslady, 2018.

Em cada máscara, elabora-se uma perspectiva do uso do poder. A primeira máscara, de Tinoca, está em conflito com o poder materialista e machista. A segunda, 
da Lady Macbeth, é dominada pelo poder violento da sociedade patriarcal, e por fim, a terceira máscara revela o poder como conquista de autonomia e liberdade de cada pessoa. Cada máscara foi elaborada com a assessoria corporal de Marina Prado, diferenciando os estados aos movimentos com ênfase em ossos (Tinoca), músculos (Lady) e líquido/fluidez (Deslady). Segundo Nathalia Luiz, o momento de loucura da personagem Lady acontece

[...] no meio [...] de tanto desejo e arrogância. Mas [a loucura] é também da Palhaça, que acaba perdendo sua identidade em alguns momentos para a Lady, ao ponto de não saber quem é ela mesma. Quando chega neste ápice de loucura, morre o lado Lady e renasce muito mais forte, potente e verdadeiro a Deslady, agora em um estado completo, consciente e transformador. (Fonte: depoimento de Nathalia Luiz, por e-mail)

A peça termina num tom de emancipação, implicando a necessidade de haver mudanças culturais para que as pessoas possam superar disposições adquiridas de violência, lembrando uma afirmação de Chimamanda Ngozi Adichie (2012, p. 47-48), fonte de inspiração para a atriz Nathalia Luiz: "Tem gente que diz que a mulher é subordinada ao homem porque isso faz parte da nossa cultura. Mas cultura está sempre em transformação. [...] A cultura não faz as pessoas. As pessoas fazem a cultura".

Deslady também relembra, a todo instante, que as personagens principais, as perspectivas e narrativas de Shakespeare sempre foram pela óptica masculina, não somente por ele ser um autor homem, mas porque a dramaturgia foi produzida no contexto da sociedade patriarcal do final do século XVII. A ressignificação construída em Deslady (2018) busca a libertação da voz feminina, não apenas da palhaça presente no solo, mas no fluxo e no eco milenar de mulheres que foram apagadas da história da humanidade pelo ponto de vista androcêntrico. Essa voz se manifesta, também, com a participação do público num momento em que a palhaça convida espectadoras mulheres a se colocarem sobre o que fariam se tivessem poder

Em depoimento para o programa, a diretora Andréa Macera, ${ }^{8}$ cuja prática tem como referência principal a metodologia de construção de máscaras da canadense Sue Morrison e de seu mentor Richard Pochinko (Coburn \& Morrison, 2013), ponderou o seguinte:

Dirigir um solo feminino, de palhaça, inspirado em Lady Macbeth, trouxe muitos elementos sobre o que chamamos de palhaçaria feminina. As mulheres se tornaram palhaças há poucos anos, entre 60 e 70 anos. A composição desta figura feminina veio repleta de elementos das outras artes, como por exemplo o teatro, a dança, os saberes circenses, entre outras habilidades e realidades ligadas a história da condição da mulher na sociedade. Em Deslady, pudemos viver e ver nascer um trabalho que cruza todas as maneiras entre teatro e palhaçaria, riso e tragédia, feminismo e humanidades. Este desafio foi e será um ótimo exemplo para nós mulheres palhaças. (Fonte: Programa da peça Deslady, 2018)

\footnotetext{
${ }^{8}$ Andréa Macera tem uma prática extensa como palhaça Mafalda Mafalda e professora de palhaçaria feminina no estado de São Paulo. O seu solo "Sobre Tomates, Tamancos e Tesouras" segue com repercussão nacional. Andréa foi idealizadora e é curadora do Encontro Internacional de Mulheres Palhaças, que tem sua terceira edição em 2018.
} 
Em Deslady, os diálogos com o texto fonte de William Shakespeare assemeIham-se ao conceito de paródia, em conformidade com os estudos teóricos de Linda Hutcheon, que compreende a paródia não só como uma repetição com diferença, mas um modelo complexo de transcontextualização, inversão e revisão crítica. Esse modelo paródico do século XX, estudado por Linda Hutcheon, recai sobre as subversões realizadas em relação às convenções da forma parodiada e a abordagem criativa que se faz da tradição, permitindo o estabelecimento das diferenças decorrentes do paralelismo. De modo similar à transmissão de outras peças de Shakespeare, Deslady envolve procedimentos de apropriação de um autor canônico e representativo do pensamento europeu androcêntrico (Rauen, 2009).

A construção dramatúrgica de Deslady ocorre por meio da justaposição de múltiplas vozes que são costuradas, como uma colcha de retalhos, tendo como cerne a ressignificação, a apropriação e a parodização da obra shakespeariana, que é atravessada e transformada pelo discurso feminista e das agentes de criação. A fábula aparece como uma paisagem impressionista, com uma figuração mais ou menos estruturada em que o distanciamento, e não a catarse, nos levam à reflexão. ${ }^{9}$

A atriz Nathalia Luiz declara que, ao reler Macbeth, em 2015, quando começou a conceber um projeto para edital de fomento, teve uma enorme dificuldade de chegar ao final da obra, mas assim resumiu o seu percurso:

[...] não aguentava mais ver tanto sangue, tanta tragédia. [...] por qual motivo queria fazer um espetáculo me inspirando em algo tão sangrento e em uma protagonista tão manipuladora? Passei dias em crise sem conseguir ir até o fim, mas cheguei e tive a coragem de desabafar, com a Margie Rauen, toda essa angústia e decepção com a minha ideia em fazer Lady Macbeth como Palhaça. E foi aí que a Margie me questionou: Que tal, ao invés de ir pela cultura da guerra e do poder, você, enquanto Palhaça, ir pela cultura da paz, transformando essa Lady em Deslady, fazendo o oposto? Eu, mais que depressa me animei e disse sim. As ideias começaram a fluir melhor. $\mathrm{E}$ eu fui pensando em outras mulheres para agregar ao projeto. [...] Não aprovamos o projeto da primeira vez. Mas [...] continuei persistindo e o aprovamos no programa de Mecenato da Fundação Cultural de Curitiba. [...] a relação do oposto entre Lady Macbeth e a Deslady foi ficando cada vez mais evidente. O poder de manipulação da Lady e o desejo do poder pelo poder, pela coroa foi sendo refletido historicamente e, trazendo o poder soberano da Lady para os dias de hoje [...] fomos encontrando em que lugar essa figura se destaca e oprime e qual seria a voz de Deslady em meio de tudo isso. Dando continuidade a pesquisa fui até São Paulo, trabalhar com a diretora Andréa Macera [...] já no primeiro dia percebi que a Lady Macbeth quer ter o poder sobre o outro, e o/a palhaço/a quer ter poder sobre ela mesma. Isso abriu minha cabeça para muitas coisas, principalmente para trabalhar em um estado de profundidade [...] Trazendo todo o meu poder de transformação também para esse trabalho. E assim aconteceu... (Fonte: Depoimento de Nathalia Luiz, por e-mail)

Outras participantes da equipe de criação ofereceram depoimentos sobre o diferencial de seu trabalho, considerando a experiência com Deslady na peça e na vida. Contamos com as reflexões da iluminadora Nadja Naira, da cenógrafa Genia Lemos, da preparadora vocal Michelle Pucci, e das figurinistas Fabianna Pescara e Renata Scrobot (também aderecista).

\footnotetext{
${ }^{9}$ Esse distanciamento se assemelha à abordagem brechtiana de quebra da ilusão teatral, embora a direção tenha aplicado procedimentos de composição de máscaras, ao invés de princípios de Bertolt Brecht, enquanto a composição dramatúrgica tenha caminhado para o diálogo rapsódico (Sarrazac, 2012).
} 
A iluminadora, Nadja Naira, tem por hábito dialogar com os pesquisadores e criadores desde o início do processo da composição artística de seus trabalhos. Na peça Deslady não foi diferente,

[...] colaborando com ideias desde a organização da sequência do roteiro das cenas, até a forma de execução das propostas pela atriz-palhaça. Todas as criadoras estavam bastante receptivas e buscavam expressar suas opiniões e conquistar seus espaços. Todas nós viemos de formações pessoais e artísticas muito diferentes, e acredito que a diversidade de técnicas e de conhecimentos enriqueceram bastante a pesquisa, fortalecendo as escolhas finais. A iluminação, além de pontuar situações, criar ambientes e climas, e permitir a visibilidade de uma obra cênica, sempre é um acabamento estético e procura juntar os elementos de espaço de apresentação, cenografia, figurino, adereços e encenação. As cores usadas na luz (basicamente ambar e vermelho) são sugestão da cor dourada usada no cenário e dos textos ditos na peça. Essas cores também ajudam a destacar o figurino e os adereços, que nessa peça são de um personagem extraordinário. A coroa e o figurino da Lady atuam como elementos dramatúrgicos que provocam o diálogo conflituoso da peça. [...] O contato com as técnicas de palhaçaria e a convivência com uma equipe ativa e animada me provocaram a olhar meu cotidiano com um pouco mais de leveza e humor. [...] A proposta de mudança de paradigmas e de maneiras de agir, buscando um pouco menos de crítica e um pouco mais de riso, podem me transformar em uma pessoa mais suave. Essa é uma busca antiga pra mim e me parece que aos poucos, com olhos e ouvidos realmente abertos, posso caminhar e continuar produzindo sonhos, realizando encontros e buscando belezas com um sorriso tranquilo. Todos os processos nos modificam um pouco na forma de trabalhar e na forma de levar a vida.

A cenógrafa Guenia Lemos reconhece inúmeras maneiras de realizar um processo de criação de cenografia, inclusive os que são predominantemente orientados pelo diretor. Relata ter participado, como atriz, em várias produções nas quais se utilizou " [...] uma maquete mostrando exatamente o que será o cenário, onde os atores já iniciam seus primeiros ensaios marcando a cena, levando em conta cada item cenográfico e onde ele ficou determinado que estará no palco" (Fonte: Depoimento de Guenia Lemos, por e-mail). Durante o trabalho coletivo de Deslady, Guenia Lemos descreve a descoberta do cenário por outro caminho,

[...] de uma forma gradativa, porque o processo exigia que dramaturgia, movimentos, figurinos, cenários, tudo fosse surgindo organicamente com o trabalho da palhaça Tinoca. Uma vez concebido o cenário, no entanto, houve uma necessidade muito grande de produzi-lo com rapidez para mergulhar mais fundo na dramaturgia e criação de cena. Esse foi um desafio. Ajustar esse tempo para permitir uma criação orgânica e que partisse também do que estava sendo criado na dramaturgia, ao mesmo tempo que entregando-o de maneira rápida o suficiente para um estudo mais profundo ainda do que poderia ser feito com ele dramaturgicamente.Também foi uma novidade para mim trabalhar no mundo da palhaçaria. Esse é meu primeiro projeto de cenário para uma palhaça e tinha que ter em mente a necessidade de um cenário compacto, leve e de fácil transporte para a longevidade do projeto. [Na peça e na vida] Deslady representa o desprendimento e desapego que temos que ter com tantas forças que nos puxam para tantos lugares perturbadores e misteriosos no dia a dia. É muito fácil se desequilibrar em momentos de fragilidade e se levar por ímpetos destrutivos (ou muitas vezes auto destrutivos), sejam eles gradativos ou não. Deslady, para mim, é o bem desapegado de qualquer necessidade que vá além do simples ser e estar em paz consigo mesma. Uma zona de equilíbrio que a maioria das pessoas desconhece. (Fonte: Depoimento de Guenia Lemos, por e-mail) 
Fabianna Pescara e Renata Scrobot enfatizaram o desafio do trabalho gradual:

Os adereços surgiram a partir das necessidades da palhaça e foram criados um a um, totalmente personalizados, assim como o figurino, que foi criado a partir de peças que ela utilizava em ensaios e improvisos, até chegarem ao seu resultado final. [Na peça e na vida] Deslady representa libertação, o que você pode fazer com o seu poder. (Fonte: Depoimento de Fabianna Pescara e Renata Scrobot, por e-mail)

A preparadora vocal, Michelle Pucci também relata o desafio de adentrar o universo da palhaçaria, mas sendo muito bem acolhida, "[...] parte de um encontro que considero inesquecível. Logo no inicio dos ensaios com a diretora Andréa Macera, percebi que seria necessário criar uma base vocal flexível, modelável, uma voz que pudesse ser vestida, junto com o belo nariz vermelho" (Fonte: Depoimento de Michelle Pucci, por e-mail). Ao longo do processo, com a atriz e palhaça, foi criada uma imagem vocal para cada figura ou máscara, de Tinoca, Lady Macbeth e Deslady :

[...] cada imagem composta de cor, direção, força, brilho, espessura, quantidade de ar. Depois ampliamos a presença dessas figuras para além da emissão vocal. Trabalhamos a escuta ativa com o ambiente e os sons incidentais, e principalmente na relação com os objetos que vinham chegando, cenário, figurinos e adereços. No nosso universo vocal, o combinado era que tudo que chegava, falava e precisava ser ouvido. O segundo desafio foi criar algo que fosse confortável para a Nathalia tendo em vista a sua condição vocal delicada. E aqui entrou minha visão do que significa desenvolver um trabalho vocal. É o que chamo de caminho da voz, seja para o teatro, para o canto ou para pessoas que queiram, de alguma maneira, melhorar sua expressão através das palavras (ou do silêncio). A peça fala, entre outras coisas, sobre uma mulher que encontra sua própria voz. Fisiologicamente falando, a Nathália precisou do apoio de uma fonoaudióloga, que foi muito potente e sensível. Quanto ao trabalho de criação, na sala de ensaios, comigo, foi de uma entrega tamanha que deu muito certo e toda essa força vocal foi à cena. Porque a voz que decide não mais se calar, é a mais poderosa de todas. [Na peça e na vida] ser Deslady, para mim, é ser livre, leve, ter voz, ser ouvida com amor. Na peça, Deslady é Nathalia em seu pretinho básico, olhos brilhantes e braços abertos para a vida. Longa vida a tudo isso. Foi um orgulho fazer parte dele e dessa transformação em todas nós. (Fonte: Depoimento de Michelle Pucci, por e-mail)

Essa costura de textos de origens diferentes para composição de Deslady a partir de uma dramaturgia shakespearina, de depoimentos pessoais da atriz, da mistura entre a arte circense, clownesca e teatral, com as intervenções da equipe de criação nos remetem as indicações de Jean-Pierre Sarrazac $(2012$, p. 83) a respeito do conceito de autor rapsodo, que opera na montagem dos elementos buscando " [...] evidenciar o ponto de vista do fabulador sobre a sociedade." Quanto à Deslady parecer um monólogo, cabe mencionar que, para Sarrazac (2012, p.73), este formato é uma tendência desde o teatro moderno e permanece no contemporâneo, sendo um reflexo também social ao "[...] dar autonomia à voz de cada um, inclusive àquela do autor-rapsodo, e operar a confrontação dialógica das vozes singulares de uma época". Podemos, porém, aproximar o texto de Deslady à conceituação de diálogo rapsódico, na medida em que costura - e descostura - modos poéticos diferentes (lírico, épico, dramático, argumentativo): 
[...] o sujeito rapsódico apresenta-se como um sujeito dividido, ao mesmo tempo interior e exterior à ação. A exemplo dos personagens dos jogos de sonho strindberguianos. Ou das criaturas beckettianas, sempre à escuta do outro, do parceiro, ainda que o outro em si mesmo, e sempre, simultaneamente, esteja numa relação de endereçamento ao espectador. (Sarrazac, 2012, p. 71-72).

Portanto, a construção dramatúrgica de Deslady possui traços de um hibridismo de discursos e linguagens textuais. É criado um solo que suplanta a ideia de monólogo, pois existe sempre um endereçamento, um diálogo com o espectador. A obra existe aparentemente de forma autônoma, mas ao mesmo tempo, só existe na relação com o público, que possui voz ativa no espetáculo.

\section{De olhares a olhares...}

Em sua jornada de desvencilhar-se da dinâmica patética do poder violento, que também afeta as mulheres, Tinoca/Deslady conversa com a sabedoria dos bobos de Shakespeare, por meio da paródia e da palhaçaria feminina. De um ponto de vista feminista, Deslady nos leva aos lugares de mulheres que seguem buscando alternativas para mostrar o avesso e subverter as práticas de poder baseadas em opressão, dominação e usurpação. Seja coroa, cetro, caneta ou liberdade, o objeto de usurpação sempre envolve um dilema de identidade, a imposição da subalternidade e a insuportavelmente obsoleta tensão inerente à estupidez do autoritarismo. ${ }^{10}$

Os argumentos sexistas de que as mulheres deixam de ser feministas quando casam ou quando contas precisam ser pagas, tanto quanto as acusações de serem vagabundas, histéricas, loucas, vítimas ou carentes quando se colocam politicamente ainda não deixaram de existir no Brasil e em outras partes do mundo. As mulheres seguem enfrentando clichés quando buscam uma carreira, se sustentam com o próprio trabalho ou lutam abertamente contra o abuso e outros tipos de violência. Sem alternativas, mulheres e homens também se tornam machistas para sobreviverem em culturas masculinas violentas. Algumas pessoas, independentemente do seu gênero, se suicidam quando não conseguem mais suportar as armadilhas do poder ilusório. Assim, as culturas de poder e violência não deveriam ser tratadas como assuntos políticos de direita e esquerda, mas enquanto problemas de sociedade, saúde e educação. Nada pior do que o corrente uso das expressões politicamente correto e incorreto para definir atitudes saudáveis e ideais pautados numa ética de cuidado, conexão e respeito.

Na poética participativa de Deslady, a atriz e palhaça Nathalia Luiz, após a temporada, diz que foi "[...] muito fiel ao processo de criação, mas aos poucos [foi se] soltando e vivendo o momento com o que o público passou a trazer". (Fonte: Depoimento de Nathalia Luiz, por e-mail). Desestabilizar e livrar-se de Macbeths, Ladies Macbeth e tragédias é tornar-se Deslady. Mas isto não se faz num passe de mágica, não é jogo rapido ou definido. Requer abandonar padrões violentos de comportamento, na vida e nas obras ficcionais, padrões que diferentes públicos irão relacionar com trajetórias pessoais diversas.

${ }^{10}$ Uma versão anterior de partes deste texto, assinado pela primeira autora, consta do programa da peça. 


\section{Referências}

ADICHIE, Chimamanda Ngozi. Sejamos todos feministas. Tradução: Christina Baum. Versão em PDF: São Paulo. Editora Schwarcz s.a. 2012. Disponível online.

BEAUVOIR, Simone de. O Segundo Sexo. Trad. Sérgio Milliet. 2 ed. Rio de Janeiro: Nova Fronteira, 2009.

BOLOGNESI, Mário Fernando. Palhaços. São Paulo: Editora UNESP, 2003.

BOURDIEU, Pierre. A Dominação Masculina. Trad. Maria Helena Küehner. 11aㅡ Ed. Rio de Janeiro: Bertrand Brasil, 2012.

CARREIRA, André L. A. N. Teatro de grupo: reconstruindo o teatro? DAPesquisa, v. 1, p. 1-7, 2008.

COBURN, Veronica; MORRISON, Sue. Clown through mask. The pioneering work of Richard Pochinko as practiced by Sue Morrison. Bristol: Intellect, The Mill; Chicago: Intellect, The University of Chicago Press, 2013.

DORNELES, Juliana Leal. Clown, o avesso de si: uma análise do clownesco na pós-modernidade. Dissertação de Mestrado. Universidade Federal do Rio Grande do Sul. Instituto de Psicologia. Porto Alegre, 2003. Disponível em http://hdl.handle. net/10183/2370.

FERNANDES, Silvia. Grupos teatrais: anos 70. Campinas: Unicamp, 2000.

HOLINSHED. Chronicles. 1587. Disponível em https://www.historyofroyalwomen. com/gruoch/gruoch-real-lady-macbeth/

HUTCHEON, Linda. Uma teoria da adaptação. 2 ed. Trad. André Cechinel. Florianópolis: Ed. da UFSC, 2013 (1 ed. em língua inglesa, Routledge, 2006).

MCMULLAN, Gordon; ORLIN, Lena Cowen; VAUGHAN, Virginia Mason (organizadoras). Women Making Shakespeare. Text, reception and performance. London: Bloomsbury, 2014.

PERROT, Michelle. Minha História das Mulheres. Trad. Angela M. S. Corrêa. 2 ed. São Paulo: Contexto, 2017.

RAMALHO, Erick. Shakespeare e o drama satírico. Aletria: Revista de Estudos de Literatura, vol. 19, Nr. Especial, 2009. Disponível em http://www.periodicos.letras.ufmg. br/index.php/aletria/article/view/1506 
RAUEN, Margarida Gandara. Casos de apropriação e transformação de peças de Shakespeare. IN CAMATI, Anna Stegh e Célia Arns de Miranda (organizadoras). Shakespeare sob multiplos olhares. Curityba: ed. Solar do Rosário, 2009, p. 185-200.

Apropriação criativa dos cânones em novos roteiros e linguagens. Ilha do Desterro. A Journal of English Language, Literatures in English and Cultural Studies. Florianópolis, 2005, (49), p. 369-396. Disponível em http://www.redalyc.org/articulo. oa?id=478348687018

ROSSI, Alice S. The Feminist Papers. From Adams to de Beauvoir. New York: Bantam, 1973.

SANTOS, Sarah Monteath dos. Mulheres palhaças: percursos históricos da palhaçaria feminina no Brasil. 2014. 180 f. Dissertação (mestrado), Universidade Estadual Paulista Júlio de Mesquita Filho, Instituto de Artes, 2014. Disponível em http://hdl.handle. net/11449/108810

SARRAZAC, Jean-Pierre (org.). Léxico do drama moderno e contemporâneo. Trad. Andre Telles. São Paulo: Cosac Naify, 2012.

SHAKESPEARE, William. Macbeth. Tradução de Beatriz Viégas-Faria. Porto Alegre: L\&PM, 2000.

Recebido em: 01/10/2018 Aprovado em: 15/10/2018 